\title{
Long-term effects of splint therapy in patients with posttraumatic stress disease (PTSD)
}

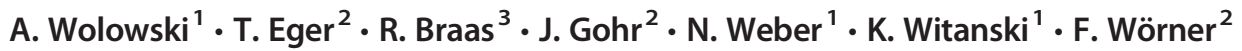 \\ Received: 8 January 2019 / Accepted: 23 December 2019 / Published online: 16 January 2020 \\ (C) The Author(s) 2020
}

\begin{abstract}
Objectives The aim of a pilot study was to clarify the question of whether mouth opening restrictions in patients with PTSD by means of splint therapy (st) show long-term therapeutic effects in the case of functional disorders.

Material and methods In 31 of 36 inpatients (soldiers, average age $37.1 \pm 7.3$ years, $26.7 \pm 2.1$ teeth) with confirmed posttraumatic stress disorder, chronic pain intensity $\geq 6$ (visual analogue scale 0 to 10 ), the mouth opening was determined, and the functional status (RDC-TMD) was recorded. All participants received a splint that was worn at night. A control of the therapeutic effect of the splint occurred after 6 weeks, 3, 6, and 12 months.

Results The mouth opening initially had an average of $30.9 \pm 6.5 \mathrm{~mm}$ (median $31 \mathrm{~mm}$ ). The pain intensity (PI) was reported to be on average VAS $8.3 \pm 0.9$, the chronic degree of pain according to von Korff was $3.9 \pm 03$. Six weeks after the st $(n=31)$, the average mouth opening was $49.5 \pm 6.3 \mathrm{~mm}$ (median 51.5). PI was given as VAS $2.3 \pm 1.1$ on average. After 3, 6 , and 12 months, 24,15 , and 14 subjects could be interviewed regarding PI. Based on the last examination date of all subjects, the average PI was given as $1.1 \pm 0.9$ (median 1).

Conclusion The presented data show that the therapeutic short-term results achieved by means of a splint remain valid on the long term despite continued PTSD.

Clinical relevance The presented study shows that patients will benefit in the long term from a splint and remain symptom-free, even if this mental illness persists.
\end{abstract}

Keywords CMD $\cdot$ Splint therapy $\cdot$ PTSD $\cdot$ Bundeswehr soldiers

\section{Introduction}

The finding that orofacial dysfunctions are more likely to be triggered and maintained by systemic, metabolic, structural,

A. Wolowski

wolowsk@uni-muenster.de

1 Poliklinik für Prothetische Zahnmedizin und Biomaterialien, Bereich Psychosomatik und Psychopathologie in der Zahnheilkunde, Zentrum für Zahn-, Mund- und Kieferheilkunde, Albert-Schweitzer-Campus 1/W30, Zentrum ZMK, D 48149 Münster, Germany

2 Abt. XXIII, Zahnmedizin, Parodontologie und Truppenzahnmedizin Bundeswehrzentralkrankenhaus Koblenz, Rübenacherstr. 170, D 56072 Koblenz, Germany

3 Abt VI, Zentrum für seelische Gesundheit, Bundeswehrzentralkrankenhaus Koblenz, Rübenacherstr. 170, D 56072 Koblenz, Germany traumatic, and psychosocial causes than by occlusal factors is particularly reflected in recent research on this disease [1]. However, it should be noted that splint therapy is the first choice for diagnosed muscle and/or temporomandibular joint diseases [2]. This is associated with high costs for the social insurance provider as well as for those affected. Against this background, the question arises as to whether clinically measurable apparent relief after splint therapy is based on veritable therapeutic effects or only on placebo effects. In the case of the latter, it would be expected that relief would be given in the short term, but that it would abate significantly after 3 months. This is supported by the results of a meta-analysis by Kuzmanovoc Pficer et al. [3]. The authors show that the positive short-term effects (up to 3 months) of splints are significant, whereas these effects did not persist on the long-term when compared to presently accessible data about control groups. Studies by Ficnar et al. [4] and Weggen et al. [5] distinguish functional from dysfunctional pain and could demonstrate that the effect of splints on proven chronification, as defined by pain duration and psychosocial 
factors, diminishes or is comparable to the effects of physiotherapy and medication. This raises the question as to whether it is more appropriate for chronic complaints, at least in cases with a clear psychosocial component of the disease, to forego the short-term effects of a splint therapy and to invest in adequate psychotherapy at an early stage.

\section{Aim of the study}

It should be verified if a splint therapy with high psychosocial stress and chronic pain as well as functional limitations in the form of a limited mouth opening has long-term effects. Outcome variables were mouth opening and pain intensity (visual analogue scale range $0-10$ ).

\section{Material and method}

Initially, 36 inpatient Bundeswehr soldiers (Department of Mental Health of Division VI Psychiatry of the BwZKrh Koblenz) with posttraumatic stress disorder diagnosed by a specialized psychiatrist after up to 17 foreign missions (at least 1 year)(trauma event: median $3.8 \pm 3.4$ years; average age 37.1 years \pm 7.6 years, BMI $26.5 \pm 3.6,27$ smokers) were examined. Participants received cognitive processing therapy in 90-min group sessions of 6 participants and 90-120-min sessions for two individual with two psychotherapists during 912 weeks with at least 18 total sessions [6].

Of these, 31 subjects (traumatic event median $3.5 \pm$ 3.1 years, average age $37.1 \pm 7.3$ years, BMI $26.8 \pm 3.7,24$ smokers, one to 17 foreign missions, average $4.7 \pm 4,5$ confirmed PTSD diagnosis for an average of $4.6 \pm 3.1$ years (median 3.5 years)) fulfilled the required inclusion criteria of at least grade 3 chronic pain according to von Korff's chronic pain scale [7]. Pain sensation was of at least 6 on an initial examination visual analogue scale from 0 to 10 . The myogen restricted oral opening was of less than $40 \mathrm{~mm}$, which was also subjectively rated as restricted, and pain in mandibular movements experienced as impaired, as well as attrition, which averaged one third of the clinical crown height [8]. All subjects were examined for RDC/TMD $[9,10]$. On this basis, the presence of a myogenic $\mathrm{CMD}$ requiring treatment was determined. The degree of attrition was determined according to the criteria of Wetselaar et al. [8]. All clinical examinations were performed through a calibrator calibrated for pressure measurements and repeat measurements. The course of pain was recorded over the entire study period using a visual analogue scale. All study participants received an occlusal splint with an increase up to $3 \mathrm{~mm}$ [11]. The splint was made on the basis of alginate models after habitual bite-taking and an arbitrary facebow transfer from a cast plastic in the form of a modified Schulte-type interceptor in the upper jaw [12].
Subjects were invited to follow-up visits 6 weeks, 3 months, 6 months, and 12 months after splint insertion and regular nocturnal usage. In the course of these examinations, the mouth opening was checked again after 6 weeks and each subject filled out a visual analogue scale at each follow-up appointment. The exclusion of the presence of muscle and joint diseases was based on the RDC TMD. A Friedman test was applied in order to make this statement. $P<0.0001$ (LOCF, CC).

\section{Results}

\section{Initial examination before splint therapy}

Before the splint therapy, the mouth opening was on average $30.9 \pm 6.5 \mathrm{~mm}$ (median $31 \mathrm{~mm}$, minimum 16) (Fig. 1).

The pain intensity was reported to be on average VAS $8.3 \pm 0.9$, the chronic degree of pain after von Korff[6] was $3.9 \pm 03$ (28 times grade 4) (Fig. 2), which indicates a high load and chronicity. The value of attrition was on average $4.4 \pm 0.5$ (median 4.3). One subject had an attrition index of 3 , with a pain intensity of VAS $=10$ and a mouth opening of $16 \mathrm{~mm}$, as well as a chronic pain index of 4 . In this case, it could be stated that the orofacial dysfunction was due less to grinding jaw movements than to mere compression of the teeth without lower jaw movement.

After 6 weeks $(n=31)$, the average mouth opening was $49.5 \pm 6.3 \mathrm{~mm}$ (median 51.5, minimum $38 \mathrm{~mm}$ ) (Fig. 3), pain intensity was given as VAS $2.3 \pm 1.1$ on average (Fig. 2). A test person indicated an intensity of 6 in the VAS. The initial mouth opening in this case was $19 \mathrm{~mm}$, the value after 6 weeks improved to $40 \mathrm{~mm}$.

The increase in mouth opening was significant $(\leq 0.05)$ and averaged 19.3 $\pm 9.3 \mathrm{~mm}$ (median 20) (Fig. 3).

After 3, 6, and 12 months, 24, 15, and 14 subjects could be interviewed regarding pain intensity (Table 1).

A deterioration of the mouth opening was not described by the subjects in the context of the re-evaluation after 3, 6 and 12 months.

The subject, who after 6 weeks in the VAS still indicated an intensity of 6 , felt the pain after 3 months with the same intensity. Only after 6 months the situation improved to VAS 4 and after 12 months to VAS 2 (Fig. 2).

Pain intensity and mouth opening correlate negatively (Spearman's correlation, BL $=-0.488$, after 6 weeks 0.477 ; significance level $p<0.01$ (two-tailed)).

\section{Drop-out}

Looking at the subjects who could not be re-examined in the course of the study, it can be seen that after 3 months, those 7 subjects who had VAS $=1$ after 6 weeks no longer appeared. One of these subjects reappeared at 6 and 12 months with the first follow-up (after 6 weeks) remaining unchanged. All subjects who did not appear after 3 months had a mouth opening of at 
Fig. 1 The mouth opening in $\mathrm{mm}$ of the incisal edge distance before splint therapy $(n=31)$
Number

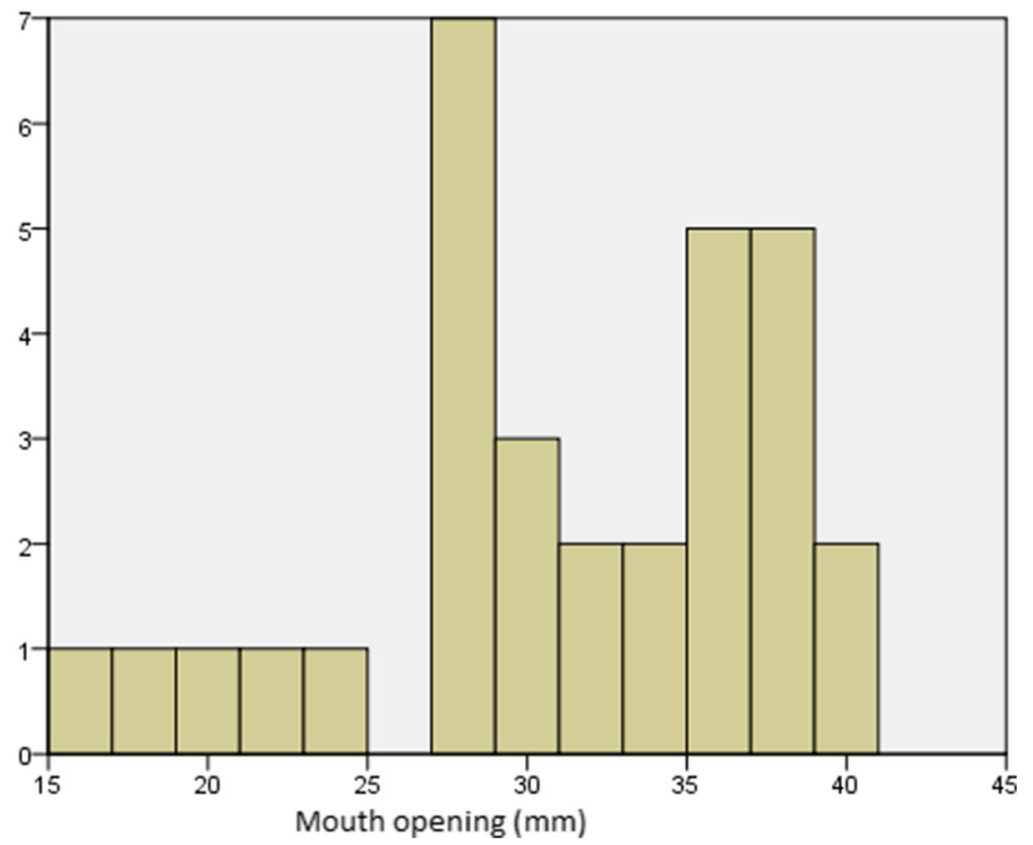

least $38 \mathrm{~mm}$ (average $42 \mathrm{~mm}$ ) after 6 weeks. According to von Korff, 5 subjects initially had the chronic pain grade 4 [6]. After 6 months, another 10 subjects did not appear. These had a mouth opening of at least $50 \mathrm{~mm}$ after 6 weeks (average $53.1 \mathrm{~mm}$ ), 7 subjects showed the value 0 on the VAS after 3 months. Three had the value 1 . After 12 months, another subject did not appear with a mouth opening of $53 \mathrm{~mm}$ at 6 weeks and VAS from 1 at 3 and 6 months.

Mean values and medians resp. in this context are used to render the results more tangible and to give the reader an impression of the issue. In the case of $n=31$, the variables mouth opening, visual analogue scale, chronical pain, and attrition index are not normally distributed (Shapiro-Wilk test: $p<0.001, p=0.046, \mathrm{p}<0.001, p=$

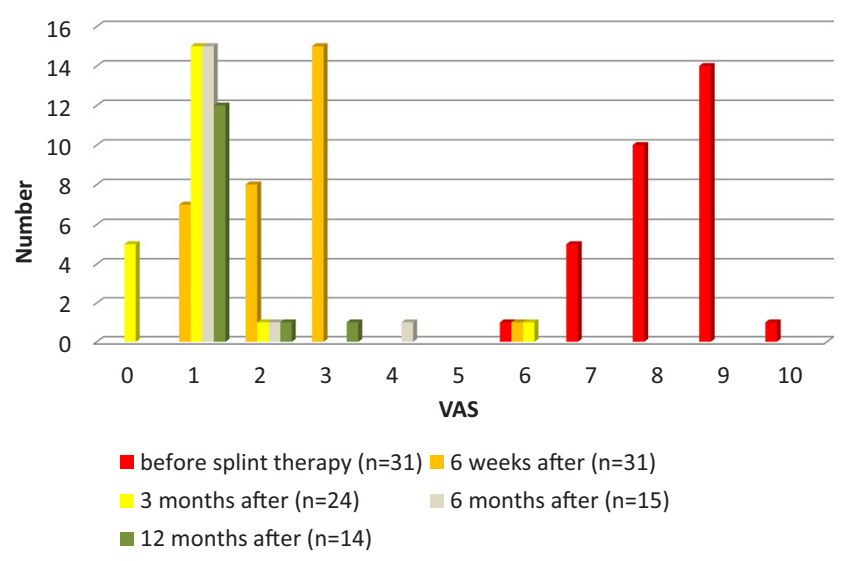

Fig. 2 The pain intensity before splint therapy as estimated by the subjects $(n=31)$ using a visual analogue scale from 0 (no pain) to 10 (worst pain imaginable), 6 weeks after the start of the splint therapy ( $n=$ $31), 3$ months after the start of the splint therapy $(n=24), 6$ months after the start of the splint therapy $(n=15), 12$ months after the start of the splint therapy $(n=14)$
0.009). In the case of $n=14$ (Complete Case Analysis), the visual analogue scale is not normally distributed $(p=0.035)$, whereas the mouth opening $(p=0.820)$ and the attrition index $(p=0.207)$ are normally distributed, and thus mean values and medians provide a legitimate description of the case (mouth opening: $28.62 \mathrm{~mm} \pm 6.8$, median 29; attrition index: $4.4 \pm 0.66$, median 4.3). Chronical pain is constant at 4 in the $\mathrm{CC}$ analysis.

\section{Discussion}

The results of the presented study show that the symptoms of myogen restricted mouth opening and pain in chronified stage and diagnosed chronic PTSD which are subjectively experienced as being the strongest could be treated by splint therapy in the short term (results after 6 weeks) and the long term (results after 12 months). It is unlikely that the effects of a splint therapy come from the removal of occlusal disorders, as these, if present, were already eliminated by attrition, which was noted in all subjects, before the onset of splint therapy. It can be assumed that the change brought by the splint alone causes effects in the sense of a reorganization of functional processes [13], which results in a relief of damaged structures [14]. In this case, however, it would be expected that after the established restructuring of the new functional patterns, there would be a risk that complaints would reappear in this new position, especially in the context of severe psychological stress and thus prevent positive long-term effects. The lack of such recurrences was explained by the fact that the splints were worn for a maximum of $8 \mathrm{~h}$ during the night and therefore there was always a change in the functional patterns and, given the severity of the 
Fig. 3 The mouth opening in $\mathrm{mm}$ of the incisal edge distance 6 weeks after the start of the splint therapy $(n=31)$

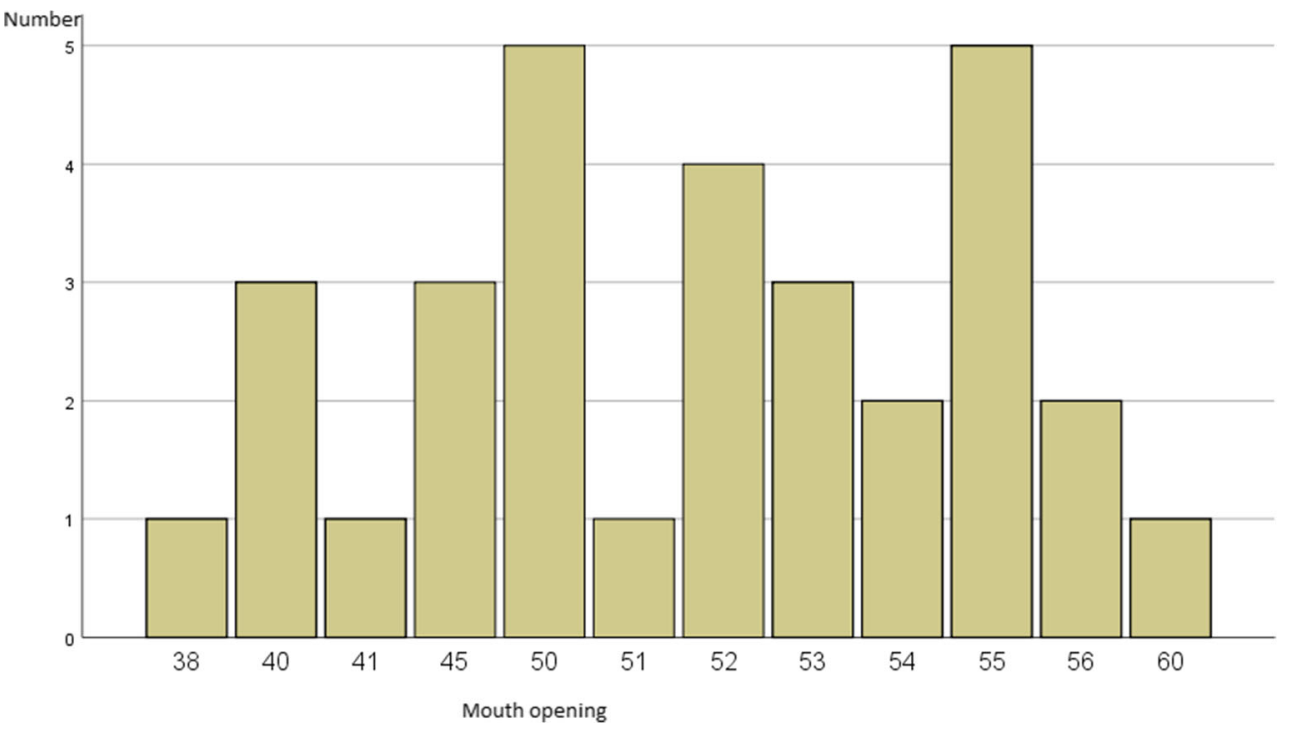

PTSD, it could not be ensured that the splints were always worn reliably so that one could assume that there was a rather intermittent mode of support, the benefits of which Manfredini et al. ${ }^{10}$ and Matsumoto et al. [15] pointed out.

It cannot be ruled out that the splint therapy was found to have a placebo effect $[16,17]$, as all the examined subjects experienced the appreciation expressed in the study, the resulting significance of their own person, and the affection as thoroughly positive. In the case of sole placebo effect, however, it would be expected that these effects diminish, and complaints reappear with decreasing attention by the examiner.

\section{Limitation of the study}

Only 14 subjects could be followed over the entire period. This corresponds to a drop-out rate of $55 \%$, which is considered to be high. However, looking at the individual cases, it becomes clear that these subjects are exclusively those who had no more distressing CMD symptoms the last time they were examined and who always had the option that they could come back in

Table 1 Average values on the visual analogue scale after 3, 6, and 12 months.

\begin{tabular}{|c|c|c|c|c|}
\hline & & $\begin{array}{l}\text { VAS after } \\
3 \text { months }\end{array}$ & $\begin{array}{l}\text { VAS after } \\
6 \text { months }\end{array}$ & $\begin{array}{l}\text { VAS after } \\
12 \text { months }\end{array}$ \\
\hline \multirow[t]{2}{*}{$N$} & Valid & 24 & 15 & 14 \\
\hline & Missing & 7 & 16 & 17 \\
\hline \multicolumn{2}{|c|}{ Average } & .96 & 1.27 & 1.21 \\
\hline \multicolumn{2}{|c|}{ Median } & 1.00 & 1.00 & 1.00 \\
\hline \multicolumn{2}{|c|}{ Hour variance } & 1197 & .799 & .579 \\
\hline \multicolumn{2}{|c|}{ Minimum } & 0 & 1 & 1 \\
\hline \multicolumn{2}{|c|}{ Maximum } & 6 & 4 & 3 \\
\hline
\end{tabular}

case of another deterioration. The key messages and analyses do not differ. This applies to their mean values, complete case analysis (CC, $n=31)$ and last observation carried forward (LOCF, $n=14$ ). It cannot be ruled out that ongoing PTSD therapy has led to the reduction of symptoms. On the other hand, an inclusion criterion was that the disorder had existed for at least 1 year, and the subjects were diagnosed on average $4.6 \pm 3.1$ years before the start of the study, which allows a chronic disorder to be assumed that usually needs an average treatment of more than 36 months because war veterans seem to be a group of patients that benefit only moderately or not at all from medication [18-21].

Sherman [22] ${ }^{2}$ uses the available literature on controlled studies to examine the empirical evidence for the effectiveness of psychotherapeutic treatment in PTSD. He was able to include 11 war trauma studies and 6 non-war-related trauma studies, totaling 690 patient treatments from 17 studies. Sherman found a significant efficacy of psychotherapeutic interventions in PTSD, which remained stable at follow-up examinations.

Although most studies on cognitive-behavioral procedures are available, it cannot be concluded that a method of treatment is superior. Rather, it can be assumed that all treatment approaches contain common and effective elements of treatment. The efficacy of psychotherapeutic treatment in posttraumatic disorders can be confirmed [23].

This suggests that within the first 6 weeks of study, this disorder was highly likely to persist and the improvement in orofacial symptoms cannot be attributed to effects of the PTSD therapy. The follow-up examination at 12 months included 15 (42\% of 36) subjects who could not be permanently discharged from inpatient PTSD therapy due to the severity of the disorder and a not yet successful therapy. After several weeks of individual therapy interruptions, these patients were repeatedly hospitalized for several weeks after the first 3 months. For these subjects, it can be stated that PTSD therapy could not have a decisive influence on the long-term effects of the splint therapy. 


\section{Conclusion}

The presented study shows that patients with severe mental illness and painful craniomandibular dysfunction, even if this mental illness persists, will benefit in the long term from an occlusal splint and remain symptom-free.

Funding information Open Access funding provided by Projekt DEAL. The financial support was completely carried out as a military medical special research project $12 \mathrm{~K} 1-\mathrm{S}-801414$ by the Medical Academy of the Bundeswehr.

\section{Compliance with ethical standards}

Conflict of interest The authors declare that they have no conflict of interest.

Ethical approval All human examinations described in this study were conducted with the consent of the responsible ethics committee of the Rhineland-Palatinate Medical Association (Landesärztekammer Rheinland-Pfalz), in accordance with national law and in accordance with the 1975 Helsinki Declaration (as revised). The study is registered with the processing number 837.068.14 (9307-F-) dated 26.03.2014.

Informed consent All patients included in the study have signed a consent form.

Open Access This article is licensed under a Creative Commons Attribution 4.0 International License, which permits use, sharing, adaptation, distribution and reproduction in any medium or format, as long as you give appropriate credit to the original author(s) and the source, provide a link to the Creative Commons licence, and indicate if changes were made. The images or other third party material in this article are included in the article's Creative Commons licence, unless indicated otherwise in a credit line to the material. If material is not included in the article's Creative Commons licence and your intended use is not permitted by statutory regulation or exceeds the permitted use, you will need to obtain permission directly from the copyright holder. To view a copy of this licence, visit http://creativecommons.org/licenses/by/4.0/.

\section{References}

1. Türp JC, Schindler HJ (2012) The dental occlusion as a suspected cause for TMDs: epidemiological and etiological considerations. J Oral Rehabil 39(7):502-5012. https://doi.org/10.1111/j.1365-2842.2012.02304.x

2. Glass EG, Glaros AG, McGlynn FD (2011) Myofascial pain dysfunction: treatments used by ADA members. Cranio 11(1):25-29. https://doi.org/10.1080/08869634.1993.11677937

3. Kuzmanovic Pficer J, Dodic S, Lazic V, Trajkovic G, Milic N, Milicic B (2017) Occlusal stabilization splint for patients with temporomandibular disorders: meta-analysis of short and long term effects. PLoS One 12(2):e0171296. https://doi.org/10.1371/journal.pone.0171296

4. Ficnar T, Middelberg C, Rademacher B, Hessling S, Koch R, Figgener L (2013) Evaluation of the effectiveness of a semifinished occlusal appliance - a randomized, controlled clinical trial. Head and face Medicine 9. https://doi.org/10.1186/1746-160X-9-5

5. Weggen T, Schindler HJ, Kordass B, Hugger A (2013) Clinical and electromyographic follow-up of myofascial pain patients treated with two types of oral splint; a randomized controlled pilot study. Int J Comput Dent 16:209-224

6. Resick PA, Wachen JS, Dondanville KA, Pruiksma KE, Yarvis JS, Peterson AL, Mintz J, and the STRONG STAR Consortium, Borah
EV, Brundige A, Hembree EA, Litz BT, Roache JD, YoungMcCaughan S (2017) Effect of group vs individual cognitive processing therapy in active-duty military seeking treatment for posttraumatic stress disorder: a randomized clinical trial. JAMA Psychiatry 74(1):28 36. https://doi.org/10.1001/jamapsychiatry.2016.2729

7. Korff von M, Ormel J, Keefe FJ, Dworkin SF (1992) Grading the severity of chronic pain. Pain 50 (2): 133-149. doi:https://doi.org/ 10.1016/0304-3959(92)90154-4

8. Wetselaar P, Lobbezoo F, Koutris M, Visscher CM, Naeije M (2009) Reliability of an occlusal and nonocclusal tooth wear grading system: clinical use versus dental cast assessment. Int $\mathrm{J}$ Prosthodont 22(4):388-390

9. Dworkin SF, LeResche L (1992) Research diagnostic criteria for temporomandibular disorders: review, criteria, examinations and specifications, critique. J Craniomandib Disord 6:301-355

10. Schiffman E, Ohrbach R, Truelove EE et al (2014) Diagnostic criteria for temporomandibular disorders (DC/TMD) for clinical and research applications: recommendations of the international RDC/TMD consortium network and Orofacial pain special interest group. J Oral facial pain headache 28:6-27. https://doi.org/10.11607/jop.1151

11. Manfredini D, Ahlberg J, Wincour E, Lobbezzo F (2015) Management of sleep bruxism in adults: a qualitativ systematic literature review. J Oral Rehabil 42:862-874. https://doi.org/10.1111/joor.12322

12. Schulte W (1988) Conservative treatment of occlusal dysfunctions. Int Dent J 38:28-39

13. Lewit K (1987) Chain reactions in disturbed function of motor system. Manual Medicine 3:27-29

14. Türp JC, Schindler HJ (2003) Zum Zusammenhang zwischen Okklusion und Myoarthropathien: Einführung eines integrierenden neurobiologischen Modells. Schweiz Monatsschr Zahnmed 113: 964-977

15. Matsomato H, Tsukiyama Y, Kuwatsuru R, Koyano K (2015) The effect of intermittent use of occlusal splint devices on sleep bruxism: a 4-week observation with a portable electromyographic recording device. J of Oral Rehabil 42:251-258. https://doi.org/10.1111/joor.12251

16. Kreiner M, Betancor E, Clark GT (2001) Occlusal stabilization appliances. Evidence of their efficacy. J Am Dent Assoc 132: 770-777. https://doi.org/10.14219/jada.archive.2001.0274

17. Schindler HJ, Türp JC, Sommer C, Kares H, Nilges P, Hugger A (2007) Therapie bei Schmerzen der Kaumuskulatur: Empfehlung zum klinischen Management. Schmerz 21:102-115

18. Foa E, Keane TM, Friedman JM, Cohen J (2009) Effective treatments for PTBS. The Guildford Press, Practice Guidelines from the International Society for Traumatic Stress Studies. London

19. Lawson NR (2014) Posttraumatic stress disorder in combat veterans. JAAPA 27(5):18-22. https://doi.org/10.1097/01.JAA. 0000446228.62683 .52

20. Ajdukovic D, Ajdukovic D, Bogic M, Franciskovic T, Galeazzi GM, Kucukalic A, Lecic-Tosevski D, Schützwohl M, Priebe S (2013) Recovery from posttraumatic stress symptoms: a qualitative study of attributions in survivors of war. PLoS One 8(8):e70579. https://doi.org/10.1371/journal.pone.0070579

21. Hermes ED, Rosenheck RA, Desai R, Fontana AF (2012) Recent trends in the treatment of posttraumatic stress disorder and other mental disorders in the VHA. Psychiatr Serv 3(5):471-476. https:// doi.org/10.1176/appi.ps.201100432

22. Sherman JJ (1998) Effects of psychotherapeutic treatments for PTBS: a meta-analysis of controlled clinical trials. J of Traumatic Stress 11:413-435. https://doi.org/10.1023/A:1024444410595

23. Flatten G, Gast U, Hofmann A, Knaevelsrud C, Lampe A, Liebermann P, Maercker A, Reddemann L, Wöller W (2011) S3 - Leitlinie Posttraumatische Belastungsstörung. Trauma \& Gewalt 3:202-210

Publisher's note Springer Nature remains neutral with regard to jurisdictional claims in published maps and institutional affiliations. 